\title{
Immobility Responses Affected by Potassium in Old Rats
}

\author{
Linda Garcés-Ramírez ${ }^{1 *}$, Oscar 0. Morales-Dionisio, Gonzalo Flores², José Luna-Muñoz ${ }^{3,4}$, \\ Fidel de la Cruz ${ }^{*} \#$
}

\begin{abstract}
${ }^{1}$ Departamento de Fisiología “Mauricio Russek Berman”, Escuela Nacional de Ciencias Biológicas, Instituto Politécnico Nacional, Ciudad de México, México

${ }^{2}$ Laboratorio de Neuropsiquiatría, Instituto de Fisiología, Benemérita Universidad Autónoma de Puebla, Puebla, México ${ }^{3}$ National Dementia BioBank, Ciencias Biológicas, Facultad de Estudios Superiores, Cuautitlán, UNAM, Estado de México, México ${ }^{4}$ Banco Nacional de Cerebros-UNPHU, Universidad Nacional Pedro Hernríquez Ureña, Santo Domingo, República Dominicana Email: "flacruz90@hotmail.com
\end{abstract}

How to cite this paper: Garcés-Ramírez, L., Morales-Dionisio, O.O., Flores, G., Luna-Muñoz, J. and de la Cruz, F. (2020) Immobility Responses Affected by Potassium in Old Rats. Pharmacology \& Pharmacy, 11, 235-250.

https://doi.org/10.4236/pp.2020.119021

Received: August 26, 2020

Accepted: September 27, 2020

Published: September 30, 2020

Copyright (c) 2020 by author(s) and Scientific Research Publishing Inc. This work is licensed under the Creative Commons Attribution International License (CC BY 4.0).

http://creativecommons.org/licenses/by/4.0/ Open Access

\begin{abstract}
Four immobility responses (IR): elicited by clamping, bandaging, grasping and inversion, and their modification by potassium and spironolactone was studied in old Wistar rats (body weight, $500 \mathrm{~g}$ ). When undrugged, only clamping and grasping, but not bandaging and inversion induced an IR in rats. Potassium and spironolactone significantly enhanced the duration of IR induced by clamping but not by grasping. They also induced an immobility response by bandaging, but not by inversion. The data suggest that IR induced by clamping and bandaging are somehow related to changes in the potassium serum levels. Consequently, such a relationship may be a suitable model to study some forms of paralysis in human beings which are related to changes in the potassium serum levels.
\end{abstract}

\section{Keywords}

Immobility Responses (IR), Potassium, Spironolactone, Hyperkalemia, Familial Periodic Paralysis

\section{Introduction}

The immobility response (IR) is probably better known as "animal hypnosis", a state of profound immobility and relative unresponsiveness, which can be triggered in many invertebrate and vertebrate species. Most of the IR induction methods involve placing the animal into an awkward posture that is temporarily sustained by manual restraint. The IR typically ensues as a response or reaction *These authors contributed equally to this work. 
to a constellation of tactile, proprioceptive, vestibular and sometimes visual stimuli [1]. Treatment with drugs, particularly dopaminergic blockers or opiates is powerful in potentiating IR [2] [3]. Differences in this response among species may result from differential susceptibility to the induction of IR by different stimuli. While all induction methods have certain features in common, there are subtle differences between them that may offer important clues as to the mechanisms involved in the induction of IR. Tonic immobility (TI) is induced by placing an animal on its back. Such a state is easily induced in guinea pigs [4], rabbits, and frogs, but not in an adult rat [1]. However, tonic immobility is readily exhibited in newborn rats, and its duration is potentiated with haloperidol, a dopamine antagonist at 10 days of age but not older [5].

Another kind of immobility is the dorsal immobility response (DIR), in which the animal is grasped by the skin of the dorsal surface of the neck and lifted into the air [5] [6] [7] [8]. DIR is easily induced in rabbits, chickens, guinea pigs and rats. Haloperidol in 20-day old rats potentiates DIR but not TI [5]. Haloperidol enhances the duration of DIR in adult rats [3] [5], but in infant rats has the opposite effect [9].

The IR can also be elicited by clamping (IC) the nape of the neck and placing the animal on its back [10] [11] [12]. The animal remains immobile in a ventroflexed posture, with its limbs tucked into its body. The effective stimulus for these responses is tactile pressure on the skin of the nape which can be achieved not only by an experimenter's finger or by clamping but also by an adult rat's teeth carrying neonate and young rats [11] [13]. Neonate rats are very susceptible to IR, since IR can also be elicited by placing a bandage around the head and neck, known as (IB) "bandaging" [11]. Adult rats continue to exhibit the DIR, as well as the IR elicited by clamping, but not by bandaging [11].

On the other hand, there is a connection between some forms of paralysis (an immobility form) in human beings and changes in the potassium serum levels. For instance, the "familial periodic paralysis" (FPP) is a disability characterized by an alteration in the sodium channels, as well as alterations in potassium levels. This disease is characterized by sporadic attacks of weakness and flaccid muscle. Moreover, it can show two forms: the hypokalemic [14] and the hyperkalemic [15]. These kinds of diseases can be induced by mutations, the diet, the environment and the routines of the individual.

The FPP induced by hypokalemia (Hypo PP) is characterized by levels of serum potassium less than $3.5 \mathrm{mEq} / \mathrm{L}$; it is characterized by episodes of weakness, fatigue, and in some cases myotonia, especially in eyelids. The episodes of paralysis in Hypo PP are usually evident in puberty; between the ages of 15 and 35 years old [16]. Published case series suggest the highest frequency of attacks in teenagers followed by a decreasing attack frequency in line with increasing age in both HyperPP and HypoPP [17] [18]. Hypo PP is associated with autosomal dominant genes that induce mutations in the sodium and calcium channel genes [18] [19]. Moreover, this disease can be triggered by environmental factors such as rich-carbohydrate diets, barium poisoning [20] [21] [22] [23], certain disord- 
ers such as in the renal dysfunctions related to changes in potassium levels [24] [25], and the use of diuretics [26] [27] [28]. Cases of thyrotoxic periodic paralysis (TPP) have also been reported, which is induced by an increase in the levels of thyroid hormones, which trigger episodes of hypokalemia [29].

The FPP induced by hyperkalemia (Hyper PP) is characterized by levels over $4.5 \mathrm{mEq} / \mathrm{L}$. The episodes in this disease are usually more frequent in infancy [16]. As Hypo PP, Hyper PP shows signs of muscle weakness. However, it also presents muscle stiffness, and myotonia. The duration of the paralysis in Hyper PP is less than 2 hours. In addition, the attacks in Hyper PP are more frequent and shorter than Hypo PP [30]. Unlike Hypo PP, Hyper PP is just associated with mutation in sodium channels [19] [20], however it is also triggered by environmental or external factors. These factors can trigger hyperkalemia, such as the intake of rich-potassium food (bananas, melons, potatoes, avocados, and citric juices; shifting in cellular potassium levels; a decrease in renal excretion [24] [25]; and insulin deficiency [31]. Moreover, the substitutes of sodium, laxatives, beta adrenergic blockers, inhibitors of the renin-angiotensin-aldosterone system, such as spironolactone, and diuretics can trigger hyperkalemia, as well as habits such as fasting, stress and cold temperatures. There are even reports that patients ate substances which are not food like the head of used matches [32] or red clay [33]. There have also been cases of pseudohyperkalemia, which is associated with leukemia, thrombocytosis, and renal disease [34] [35] [36], and reverse hyperkalemia, which is associated with leukemia [37] [38] [39] [40] [41].

The diagnosis for Hypo PP or Hyper PP are elaborated by the signs and symptoms in the patient, such as the serum level of potassium at the moment of the attacks, the presence of triggers as were mentioned before, cases in other members of the family and the evidence of genetic mutations related to changes in potassium levels. These disorders can trigger renal and cardiac diseases; they can even reduce the quality of life of patients who get these kinds of alterations [17] [18] [42] [43]. In both forms, paralysis is the most conspicuous symptom, the pathophysiology of which is not well understood [17] [44]. Therefore, the objective of this study was to investigate whether serum potassium levels, either by direct potassium administration or by indirectly modifying their levels by the administration of an aldosterone receptor blocker, have an effect on the duration of the immobility response elicited by four methods in rats.

\section{Methods}

All experimental procedures in this study have followed the guidelines of the Mexican government (NOM-062-ZOO-1999), which details the technical specifications for production, care, and use of laboratory animals. The internal Bioethics Committee approved this protocol.

Fifty male adult Wistar rats $(505 \pm 10 \mathrm{~g})$ were used, provided by the bioterium of the National School of Biological Sciences. All animals were individually housed, kept and tested at a temperature of $21^{\circ} \mathrm{C} \pm 1{ }^{\circ} \mathrm{C}$, and $12: 12 \mathrm{~h} \mathrm{light/dark}$ cycle, with lights on at $07.00 \mathrm{~h}$. Experimental testing began between 10.00 and 
$11.00 \mathrm{~h}$. The behavior was recorded on videotape for their posterior analysis.

\subsection{Procedure}

The following substances were administered intraperitoneally (i.p.): potassium chloride (KCl: Sigma-Aldrich) 300 and $500 \mathrm{mg} / \mathrm{kg}$ or sodium chloride $(\mathrm{NaCl}$ : Sigma-Aldrich) $0.9 \%$ and $500 \mathrm{mg} / \mathrm{kg}$. And intragastrically: Spironolactone (Aldactone, Searle) $75 \mathrm{mg} / \mathrm{kg}$. Groups of ten randomly selected rats were used for each treatment. Animals were tested just prior to injection and then each hour for the next $3 \mathrm{~h}$. Preliminary dose-response experiments in male rats of different weights $(200 \pm 10,300 \pm 10$, and $505 \pm 10)$ were conducted to determine the possible relations between body weight, treatment, and dose. Since rats that weighed 200 or $300 \mathrm{~g}$ did not respond to any treatment, such data are not shown. All drugs were administered in volumes of $3 \mathrm{~mL} / \mathrm{kg}$. Subsequently, other groups of rats were administered with the doses that showed an effect such as $\mathrm{NaCl} 300$ $\mathrm{mg} / \mathrm{kg}$ and $500 \mathrm{mg} / \mathrm{kg} ; \mathrm{KCl} 300 \mathrm{mg} / \mathrm{kg}$ and $500 \mathrm{mg} / \mathrm{kg}$, and two doses of spironolactone $(50 \mathrm{mg} / \mathrm{kg}$, and $150 \mathrm{mg} / \mathrm{kg})$ to observe the effects of these substances on the immobility responses. Because of $\mathrm{KCl} \mathrm{500,} \mathrm{mg} / \mathrm{Kg}$ showed the most persistent effects, we decided to test this dose on groups of old and young rats to test if there were differences between them.

The behavioral tests were recorded on videotape using a VHS video camera (NV-N3000PN, Panasonic) for later analysis.

\subsection{Behavioral Testing}

The immobility response (IR) was induced in all animals by the following 4 methods in the order described below. The methodology has been well established and described in previous works [2] [3] [11]. In each method of induction, all animals received four trials $(0,1,2$, and 3$)$ with an intertrial interval of $1 \mathrm{~h}$.

\subsubsection{Inversion (Also Called Tonic Immobility TI)}

To induce tonic immobility, the animal was rapidly inverted and restrained on its back for $3 \mathrm{~s}$. before removing the hand holding the imposed flank. Measurement of the duration of tonic immobility began with the release of the subject and ended when the animal returned to a prone position, standing on all four paws or until $180 \mathrm{~s}$ had elapsed.

\subsubsection{Clamping the Neck (IC)}

A clamp was applied between the base of the skull and the back of the ears, the pressure being sufficient to lift the whole animal by the clamp. The animal was then placed on a flat surface, on its side. The duration of immobility was measured from the moment it was placed on its side until the animal recovered the prone position, or to a maximum of $180 \mathrm{~s}$.

\subsubsection{Bandaging the Neck (BI)}

A bandage was snugly wrapped around the head and neck (but not tight enough as to impair breathing). The animal was then placed on its side onto a flat sur- 
face. The duration of immobility was measured as above.

\subsubsection{Grasping the Neck (Also Called Dorsal Immobility DIR)}

The animal was gently grasped by the nape of the neck between the base of the skull and the back of the ears, and was lifted off its feet, so that no part of the animal's body touched any other surface. The duration of immobility was measured from the onset of the response (which was instantaneous), until the animal made escape-like movements directed at the experimenter's hand, or until $180 \mathrm{~s}$. had elapsed.

\subsection{Analysis}

Data were analyzed using an analysis of variance for Repeated Measures on Ranks and the posteriori test (Tukey) in which comparisons of each treatment against the saline control values were made $(0.9 \%) .{ }^{*} p<0.05 ;{ }^{* *} p<0.01$

\section{Results}

The results for immobility by inversion are not shown because this kind of immobility was not presented in any time with any treatment.

Figure 1 shows the results for the duration of the immobility response induced by clamping. There was a significant increase in the duration of the immobility elicited by clamping, at 1,2 and 3 hours after the administration of $\mathrm{KCl}$ $500 \mathrm{mg} / \mathrm{kg}$ and spironolactone $75 \mathrm{mg} / \mathrm{kg}\left(\mathrm{F}_{(3)}=9.693, P<0.001\right)$. However, $\mathrm{NaCl}$ $500 \mathrm{mg} / \mathrm{kg}(P<0.857)$ and $\mathrm{KCl} 300 \mathrm{mg} / \mathrm{kg}(P<0.252)$ did not increase the duration of immobility induced by clamping versus the basal time $(0 \mathrm{~h})$. There were also differences between the treatments and the interaction (treatment $\mathrm{x}$ time) $\left(\mathrm{F}_{(4)}=4.573, P<0.003\right.$ and $\mathrm{F}_{(12)}=3.286, P<0.001$ respectively). The immobility response also was modified by the different substances administrated. Within

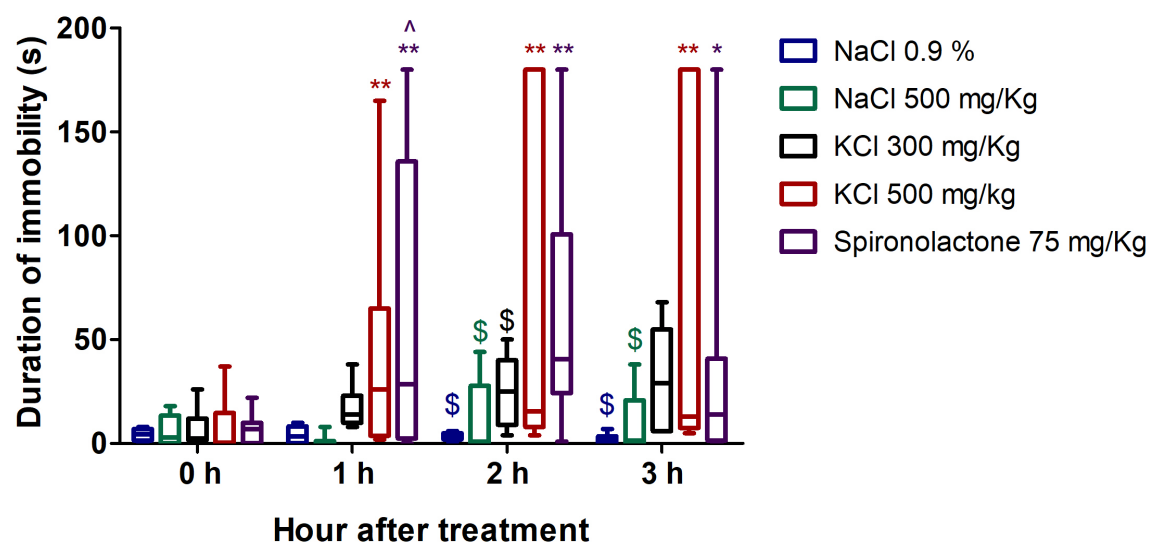

Figure 1. Effects of $\mathrm{NaCl} 0.9 \%$ (control), $\mathrm{NaCl} 500 \mathrm{mg} / \mathrm{kg}, \mathrm{KCl} 300 \mathrm{mg} / \mathrm{kg}, \mathrm{KCl} 500$ $\mathrm{mg} / \mathrm{kg}$ and spironolactone $75 \mathrm{mg} / \mathrm{kg}$ on the duration of immobility response induced by clamping. The boxes and whiskers represent the median plus the maximum and the minimum value. ${ }^{* *} P<0.01$ vs time at $0 \mathrm{~h}$ (basal); $\wedge P<0.01$ vs $\mathrm{NaCl} 0.9 \%$ and $500 \mathrm{mg} / \mathrm{kg}$, $\mathrm{KCl} 300 \mathrm{mg} / \mathrm{kg}$.; ${ }^{\circ} P<0.01$ vs spironolactone; ${ }^{\$} P<0.01 \mathrm{vs} \mathrm{KCl} 500 \mathrm{mg} / \mathrm{kg}$. Two way RM ANOVA, post hoc Tukey. 
the first hour $(1 \mathrm{~h})$ after treatment, the administration of spironolactone 75 $\mathrm{mg} / \mathrm{kg}$ significantly increased the duration of immobility by clamping versus treatments with $\mathrm{NaCl} 0.9 \%(P<0.004) ; \mathrm{NaCl} 500 \mathrm{mg} / \mathrm{kg}(P<0.002) ; \mathrm{KCl} 300$ $\mathrm{mg} / \mathrm{kg}(P<0.04)$, but there was no difference versus $\mathrm{KCl} 500 \mathrm{mg} / \mathrm{kg}(P<0.526)$. Within the second hour $(2 \mathrm{~h})$ after treatment, the administration of spironolactone $75 \mathrm{mg} / \mathrm{kg}$ and $\mathrm{KCl} 500 \mathrm{mg} / \mathrm{kg}$ increased the duration of immobility by clamping. Spironolactone $75 \mathrm{mg} / \mathrm{kg}$ was different versus $\mathrm{NaCl} 0.9 \%(P<0.006)$ and $500 \mathrm{mg} / \mathrm{kg}(P<0.024)$; and $\mathrm{KCl} 500 \mathrm{mg} / \mathrm{kg}$ was different versus $\mathrm{NaCl} 0.9 \%$, $\mathrm{NaCl} 500 \mathrm{mg} / \mathrm{kg}$, and $\mathrm{KCl} 300 \mathrm{mg} / \mathrm{kg}$. And within the third hour ( $3 \mathrm{~h})$ after treatment, $\mathrm{KCl} 500 \mathrm{mg} / \mathrm{kg}$ augmented the duration of immobility regarding $\mathrm{NaCl} 0.9 \%$ and $\mathrm{NaCl} 500 \mathrm{mg} / \mathrm{kg}$.

The immobility induced by bandaging (as we explained before) is not present in adult rats. However, the administration of $\mathrm{KCl} 500 \mathrm{mg} / \mathrm{kg}\left(\mathrm{F}_{(4)}=2.595, P<\right.$ 0.049 ) induced the immobility by bandaging in adult rats (Figure 2 ), it was different between time $0 \mathrm{~h}$ (basal) versus the third hour $(3 \mathrm{~h})$ after treatment $(P<$ 0.009). $\mathrm{KCl}$ also showed differences within the second hour $(2 \mathrm{~h})$ after treatment versus $\mathrm{NaCl} 0.9 \%(P<0.032)$ and $\mathrm{KCl} 300 \mathrm{mg} / \mathrm{kg}(P<0.047)$.

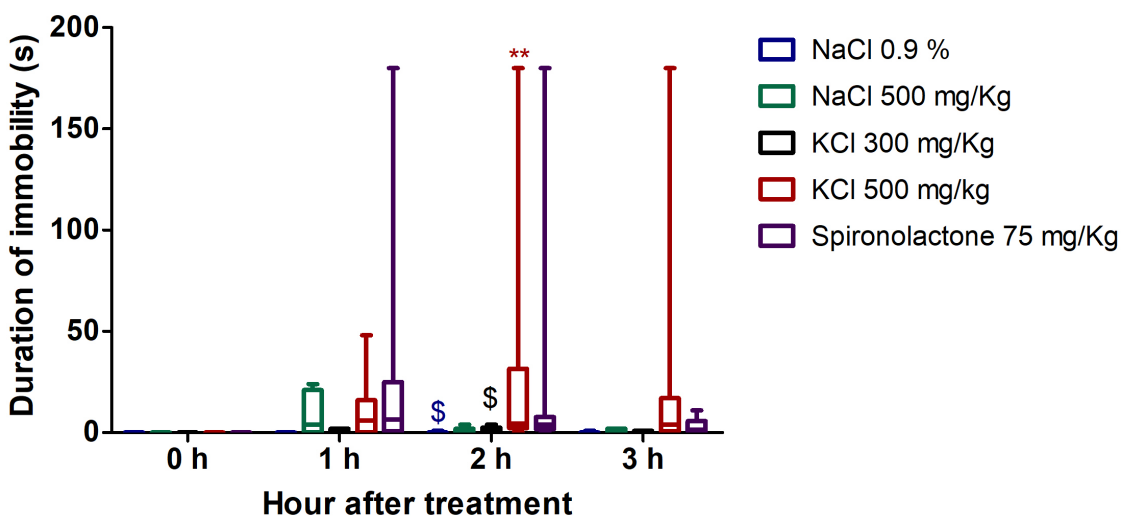

Figure 2. Effects of $\mathrm{NaCl} 0.9 \%$ (control), $\mathrm{NaCl} 500 \mathrm{mg} / \mathrm{kg}, \mathrm{KCl} 300 \mathrm{mg} / \mathrm{kg}, \mathrm{KCl} 500$ $\mathrm{mg} / \mathrm{kg}$ and spironolactone $75 \mathrm{mg} / \mathrm{kg}$ on the duration of immobility response induced by bandaging. The boxes and whiskers represent the median plus the maximum and the minimum value. ${ }^{* *} P<0.01$ vs time at $0 \mathrm{~h}$ (basal); ${ }^{\$} P<0.01$ vs $\mathrm{KCl} 500 \mathrm{mg} / \mathrm{kg}$. Two way RM ANOVA, post hoc Tukey.

Figure 3 shows the duration of immobility by grasping. This kind of immobility is presented in adult rats and we found that it is modified by the time $\left(\mathrm{F}_{(3)}\right.$ $=5.432, P<0.001)$; the treatment $\left(\mathrm{F}_{(4)}=6.165, P<0.001\right)$ and the interaction time $\mathrm{x}$ treatment $\left(\mathrm{F}_{(12)}=2.59, P<0.004\right) . \mathrm{KCl} 300 \mathrm{mg} / \mathrm{kg}$ augmented the duration of immobility by grasping at time $1 \mathrm{~h}$ after treatment $(P<0.001)$ and at $3 \mathrm{~h}$ after treatment the duration decreased $(P<0.001)$. Spironolactone $75 \mathrm{mg} / \mathrm{kg}$ augmented the duration of immobility 2 hours after treatment $(P<0.001)$ and then the immobility decreased at $3 \mathrm{~h}$ after treatment $(P<0.043)$. Within the first hour $(1 \mathrm{~h})$ after treatment, $\mathrm{KCl} 300 \mathrm{mg} / \mathrm{kg}$ increased the duration of immobility significantly versus $\mathrm{NaCl} 0.9 \%(P<0.001), \mathrm{NaCl} 500 \mathrm{mg} / \mathrm{kg}(P=0.001)$ and $\mathrm{KCl}$ 
$500 \mathrm{mg} / \mathrm{kg}(P<0.001)$. Within the second hour after treatment, spironolactone $75 \mathrm{mg} / \mathrm{kg}$ significantly increased the immobility versus the treatments of $\mathrm{NaCl}$ 0.9\% $(P<0.001), \mathrm{NaCl} 500 \mathrm{mg} / \mathrm{kg}(P<0.001)$, and $\mathrm{KCl} 500 \mathrm{mg} / \mathrm{kg}(P<0.001)$.

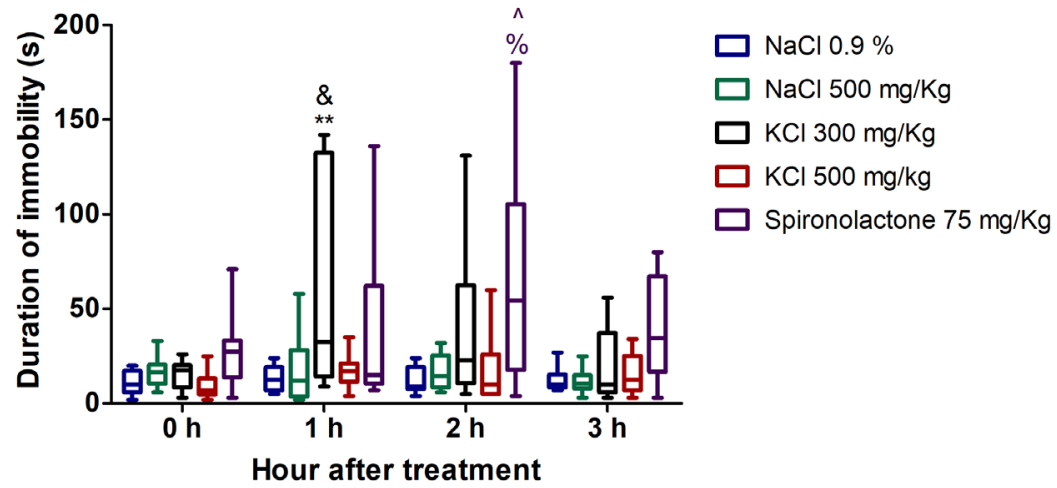

Figure 3. Effects of $\mathrm{NaCl} 0.9 \%$ (control), $\mathrm{NaCl} 500 \mathrm{mg} / \mathrm{kg}, \mathrm{KCl} 300 \mathrm{mg} / \mathrm{kg}, \mathrm{KCl} 500$ $\mathrm{mg} / \mathrm{kg}$ and spironolactone $75 \mathrm{mg} / \mathrm{kg}$ on the duration of immobility response induced by grasping the boxes and whiskers represent the median plus the maximum and the minimum value. ${ }^{*} P<0.01$ vs time at $0 \mathrm{~h}$ (basal) and $3 \mathrm{~h}$ after treatment; ${ }^{\%} P<0.01$ vs time $0 \mathrm{~h}$ (basal), $1 \mathrm{~h}$ and $3 \mathrm{~h}$ after treatment; ${ }^{\&} P<0.01 \mathrm{vs} \mathrm{NaCl} 0.9 \%, 500 \mathrm{mg} / \mathrm{kg}$ and $\mathrm{KCl} 500$ $\mathrm{mg} / \mathrm{kg} ; \wedge P<0.01 \mathrm{vs} \mathrm{NaCl} 0.9 \%, 500 \mathrm{mg} / \mathrm{kg}$ and $\mathrm{KCl} 500 \mathrm{mg} / \mathrm{kg}$. Two way RM ANOVA, post hoc Tukey.

After testing the previous substances in different doses, we used $\mathrm{KCl} 500$ $\mathrm{mg} / \mathrm{kg}$ because this salt and this dose presented the most consistent effects. $\mathrm{KCl}$ $500 \mathrm{mg} / \mathrm{kg}$ augmented the immobility response induced by clamping (Figure 4) in old rats (time: $\mathrm{F}_{(3)}=3.185, P<0.031$ and the interaction: time $\times$ age, $\mathrm{F}_{(3)}=$ $3.608, P<0.019)$ from the second hour $(2 \mathrm{~h})(P<0.002)$ and remained until the third hour $(3 \mathrm{~h})(P<0.014)$ after treatment. $\mathrm{KCl} 500 \mathrm{mg} / \mathrm{kg}$ also had a different effect increasing the duration of immobility response by clamping in old rats compared to the young rats within the second hour $(P<0.004)$ and remained until the third hour $(P<0.02)$.

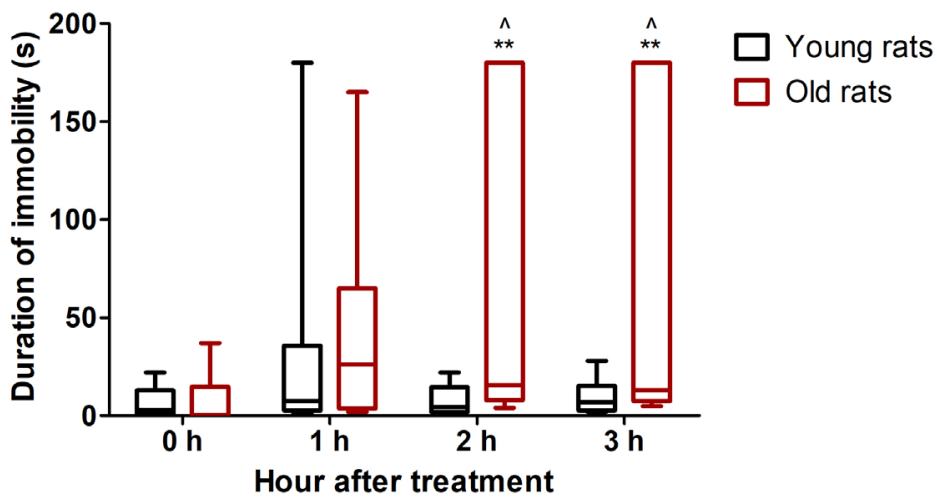

Figure 4. Effect of $\mathrm{KCl} 500 \mathrm{mg} / \mathrm{kg}$ on the duration of immobility response induced by clamping in young and old rats. The boxes and whiskers represent the median plus the maximum and the minimum value. ${ }^{\star *} P<0.01$ vs its basal $(0 \mathrm{~h}) ; \wedge P<0.01$ vs young rats. Two way RM ANOVA, post hoc Tukey. 
However, the duration of immobility induced by bandaging (Figure 5: $\mathrm{F}_{(3)}=$ 1.47, $P<0.23$ ) and by grasping (Figure $6: \mathrm{F}_{(3)}=1.816, P<0.155$ ) was not modified in old rats compared with the young rats.

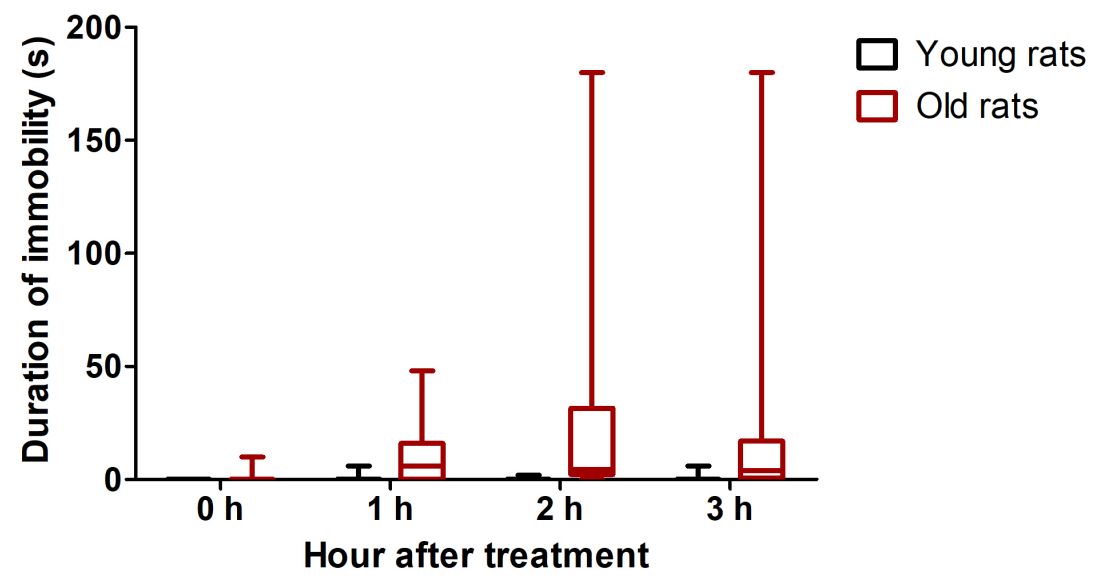

Figure 5. Effect of $\mathrm{KCl} 500 \mathrm{mg} / \mathrm{kg}$ on the duration of immobility response induced by bandaging in young and old rats. The boxes and whiskers represent the median plus the maximum and the minimum value. Two-way RM ANOVA.

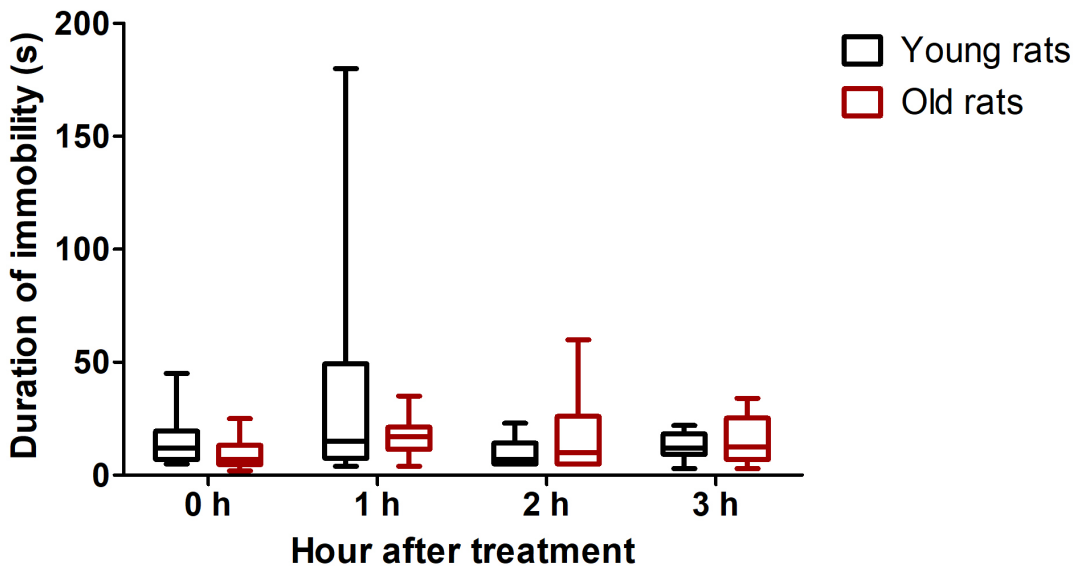

Figure 6. Effect of $\mathrm{KCl} 500 \mathrm{mg} / \mathrm{kg}$ on the duration of immobility response induced by grasping in young and old rats. The boxes and whiskers represent the median plus the maximum and the minimum value. Two-way RM ANOVA.

\section{Discussion}

The results show that the rat exhibited distinct degrees of susceptibility to induction of IR by the four methods employed. After saline injection, IR was induced by clamping and grasping, but not by inversion or bandaging. The administration of KCI or spironolactone significantly potentiated the IR duration by clamping but not by grasping and significantly potentiated the occurrence and the IR duration induced by bandaging but not by inversion. These data suggest that the most potent methods to induce immobility are clamping and grasping, followed by bandaging and finally by inversion. Both clamping and grasping involve a powerful tactile stimulus to the nape of the neck, which is sustained until 
The animal returns to the prone position (clamping) or it emits an escape-like behavior (grasping). The localized application of pressure on the skin of the nape area by both of these methods could be mimicking the mother's biting when carrying the pup or the predator's bite when attacking the prey. The bandaging procedure is similar, because the pressure is applied to an area that includes the neck, but it is different in that the bandage gives a weaker, uniform pressure around the widest area of the neck. This method may elicit some of the components of clamping-induced immobility, because it stimulates the same body area. However, it was shown that bandaging induces IR in neonates, but not in adult rats [11]. The inversion method differs more radically, because there is not a continuous stimulus on the neck during the entire period of immobility. In predator/prey confrontations in nature, the immobility of the prey decreases when the physical distance between predator and prey increase, thus permitting the prey to take advantage of opportunities to escape. However, when the predator and the prey are in a very close contact, the immobility should be potentiated. This could explain why clamping and grasping are more potent to induce the immobility response compared to bandaging and simple inversion. However, bandaging produces a weak stimulus, it still was able to produce immobility, but this was not the case with the simple inversion.

A previous study [11] demonstrates that immobility in neonate rats can be induced either by clamping or by bandaging the neck region, whereas in adult rats it can be elicited only by clamping. Therefore, we concluded that in the adult rats, the characteristics of the stimuli to induce immobility are more specific, and that such specificity is lost in mesencephalic rats [7].

Several lines of evidence indicate that the neocortex is involved in inhibiting the IR response: 1) this susceptibility decreases in the young animals at the time when the neocortex matures [45];2) the surgical decortication of unsusceptible animals can make them susceptible [45]; 3) $\mathrm{KCl}$-induced spreading depression of the neocortex also potentiates the IR [46] [47]; and 4) mesencephalic rats are more susceptible to IR than intact adult rats [48]. The mesencephalic rats are similar to neonatal rats, but have more diverse stimuli, either clamping or bandaging are capable of inducing IR.

Aging of the nervous system is critical, because all other body systems are coordinated by this system. The nervous system controls body functioning through the nerve fibers in the voluntary muscles, through the autonomic nervous system or through the signals of the brain to the endocrine system. The decline in the ability of the body to respond to stress is primarily the result of aging in the autonomic nervous system. This system regulates the internal environment of the body. It controls and regulates activities such as heart rate, blood pressure, skin temperature, digestion, elimination, respiration, and reactions to emergencies or stress.

With aging, many of the responses controlled by the autonomic nervous system become slow or weaker (including the neocortical activity) [49], so it takes longer for the body to adapt to changing conditions. This slowdown may be the 
result of changes in the synthesis of neurotransmitters, to the structural changes in neurons, or to the loss of neurons [49].

The aging autonomic nervous system manages to maintain normal body functions fairly well when no demands are placed on it, but it falters when it is faced with extreme environmental changes.

Old, neonatal and mesencephalic rats respond in a similar way to more diverse stimuli, involving either clamping or bandaging [48]. Therefore, the evidence seems to provide some basis for formulating the hypothesis that the neocortex could be "weakened" in old rats by the administration of potassium, at least for some IRs (clamping and bandaging).

These data suggest that IR and changes in the potassium serum levels are somehow related. Consequently, such a relationship may be a suitable model to study some forms of paralysis in human beings (i.e. the "familiar periodic paralysis"), which are essayed in transgenic animal models related to changes in the potassium serum levels through changes in the expression of ionic channels [50].

The effects of spironolactone $75 \mathrm{mg} / \mathrm{kg}$ were mainly on the immobility induced by clamping (Figure 1) and the immobility induced by grasping (Figure 3 ), but it had no effect either on the immobility by bandaging (Figure 2) or by inversion (Data not shown). Spironolactone on clamping had its effect at the first hour after administration and it remained until the third hour, for grasping the effect was only significant during the second hour after administration.

On the other hand, $\mathrm{KCl}$ provoked an increase in the duration of immobility on three (clamping, bandaging and grasping) of the four kinds of immobility studied. Nevertheless, there was a differential effect due to the duration of immobility by clamping and by bandaging increased only by the highest dose tested $(\mathrm{KCl} 500 \mathrm{mg} / \mathrm{kg}$ ), contrarily the duration of immobility by grasping only was augmented by the lowest dose of $\mathrm{KCl}(300 \mathrm{mg} / \mathrm{kg})$. It should be noted that the $\mathrm{KCl}$ at the highest dose $(500 \mathrm{mg} / \mathrm{kg})$ maintained its effect until the third hour after administration, whereas the $\mathrm{KCl}$ at $300 \mathrm{mg} / \mathrm{kg}$ had its greatest effect in the first hour after its administration, and then the effect was lost.

These results may reflect the relationship between serum potassium levels and the duration of the immobility responses studied. The spironolactone that is related to the increase of potassium in serum, as well as the $\mathrm{KCl}$ administered directly, increased the duration of the immobility responses that we studied. However, as already mentioned before, these immobility responses show differences in the stimuli that trigger them. We can clearly see this in how its duration was modified differently with changes in serum potassium. Thus, $\mathrm{KCl} 500 \mathrm{mg} / \mathrm{kg}$ increased the duration of clamping and bandaging, but not of grasping. Grasping did increase its duration, but only with the lowest $\mathrm{KCl}$ dose $(300 \mathrm{mg} / \mathrm{kg})$. It is possible that spironolactone increased potassium levels without becoming as high as $\mathrm{KCl} 500 \mathrm{mg} / \mathrm{kg}$. We can infer this, since spironolactone did not significantly modify the duration of immobility by bandaging, but it did change the duration of clamping and grasping. Bandaging was only modified with the high- 
est $\mathrm{KCl}$ dose $(500 \mathrm{mg} / \mathrm{kg})$. On the other hand, the duration of grasping was only modified with the lowest dose of $\mathrm{KCl}(300 \mathrm{mg} / \mathrm{kg})$ and spironolactone, and the duration of immobility by clamping was only increased with the highest dose of $\mathrm{KCl}(500 \mathrm{mg} / \mathrm{kg})$ and spironolactone. For all this, it is possible that spironolactone has increased potassium levels in the rat to concentrations between 300 and $500 \mathrm{mg} / \mathrm{kg}$.

Spironolactone is an antagonist of aldosterone (hormone involved in the regulation of sodium levels), which is released in the adrenal glands. However, due to its chemical structure, it could also have effects on other hormones released in these glands. For example, it could interfere with the activity of cortisol. In a previous study, our group found that the IR (especially clamping) and the function of the glucocorticoids such as corticosterone are in somehow related, due to a longer IR when corticosterone is administrated [51]. We also found in a model of autism in rats, that these rats had longer immobility compared to their controls. This suggests that rats subjected to this model are prone to more stress and therefore release more cortisol [52].

Comparing the results with symptoms of Hyper PP or Hypo PP, we found that high levels of potassium increase the duration of IR. In addition, we observed stiffness in immobility by clamping and by grasping, which can be similar to the effects in patients with Hyper PP, but bandaging increased their duration of immobility with $\mathrm{KCl} 500 \mathrm{mg} / \mathrm{Kg}$. However, these changes were not long-term because these rats were normokalemics, and the increase of potassium levels were returned to basal levels. The same occurred with low levels of potassium. When IR were tested at high doses of potassium or when the potassium levels were decreased through increasing the sodium levels, it showed a tendency to increase the duration of IR, that could be due to a paradoxal depolarization [24] [25] [53] [54] or another unknown mechanism.

On the other hand, $\mathrm{KCl}$ at high doses $(500 \mathrm{mg} / \mathrm{kg}$ ) showed more susceptibility in old rats to modify the duration of IR by clamping than young rats. Although immobility by bandaging increased its frequency of occurrence, it did not become significantly different from young rats. Grasping did not present differences between old and young rats. However, it is important to remember that immobility by grasping was only modified at low doses of potassium. So, it might be convenient for future studies to test $\mathrm{KCl}$ at low doses in young and old rats. In some cases, the presence of Hypo PP and Hyper PP in the patients occurs around the first decade and according to the age of the patient the paralysis are less frequent [17] [18], though it has been observed that old rats showed a major increase in the IR.

In this work we found a clear relation between high levels of potassium and the increase of the duration of immobility responses, specially clamping, bandaging and grasping. However, the effect was not exactly the same, the high levels of potassium modify the duration of these kinds of immobility differentially. As we explained before, the immobility responses can be affected by drugs, age, 
Table 1. Summary of the differential effect of the IR elicited by four immobility responses in old rats.

\begin{tabular}{ccccc}
\hline & \multicolumn{5}{c}{ Immobility } \\
\hline & Inversion & Clamping & Bandaging & Grasping \\
\hline Undrugged & - & + & - & + \\
Potassium and/or spironolactone & - & ++ & + & ++ \\
\hline
\end{tabular}

- absence of response, + presence of response, ++ response enhanced. Table 1 shows a summary of the differential effect of the IR elicited by inversion, clamping, bandaging, and grasping. When undrugged, only clamping and grasping but not inversion and bandaging induced IR in rats. Spironolactone and potassium significantly enhanced the duration of the IR by clamping and by grasping, and only potassium significantly increased the occurrence and duration of the IR by bandaging but not by inversion. Since there was no effect in the duration of the IR by inversion in animals treated with any drug, these results are not shown.

stress and even some animal models for autism, etc. [2] [3] [11] [51] [52]. Nevertheless, it had not been studied the participation of the electrolytes on the immobility responses, although it is known that an imbalance in electrolytes induce some types of paralysis such as Hypo PP and Hyper. This opens the question about how the hormones, the neurotransmitters and the electrolytes are related to affect the immobility responses in a different way.

\section{Conclusion}

To summarize, the IR which were modified by $\mathrm{KCl}$ were clamping, bandaging and grasping (as shown in Table 1) whereas the changes with spironolactone in these kind of IR were only in clamping and grasping. These effects showed that IR can be modified for changes, in this case the increase, in the levels of potassium induced by the direct administration of potassium or by administration of substances such as spironolactone that can alter the homeostasis of potassium. This could lead us to consider the immobility responses as a test to study the Hyper PP or Hypo PP.

\section{Acknowledgements}

CONACYT for fellowship: FdC, LGR, JLM and GF acknowledge the "Sistema Nacional de Investigadores" for membership.

Thanks to Robert Simpson for editing English language text.

\section{Conflicts of Interest}

The authors declare no conflicts of interest regarding the publication of this paper.

\section{References}

[1] Klemm, W.R. (1971) Neurophysiology Studies of the Immobility Reflex (“Animal Hypnosis"). Neuroscience Research, 4, 165-212. https://doi.org/10.1016/B978-0-12-512504-8.50011-1

[2] Klemm, W.R. (1989) Drug Effects on Active Immobility Responses: What They Tell Us about Neurotransmitter Systems and Motor Functions. Progress in Neurobiolo- 
gy, 32, 403-422. https://doi.org/10.1016/0301-0082(89)90030-0

[3] De la Cruz, F. and Uriostegui, T. (1996) The Differential Haloperidol Effect on the Immobility Response Elicited by Clamping, Grasping, Bandaging and Inversion in Guinea Pig, Hamster and Rat. Behavioural Brain Research, 78, 195-199. https://doi.org/10.1016/0166-4328(95)00249-9

[4] Liberson, W.T., Smith, R.W. and Stem, A. (1961) Experimental Studies of the Prolonged Hypnotic Withdrawal in Guinea Pigs. Journal of Neuropsychiatry, 3, 28-34.

[5] Meyer, M.F., Smith, R.L. and Van Hartesveldt, C. (1984) Haloperidol Differentially Potentiates Tonic Immobility, the Dorsal Immobility Response, and Catalepsy in the Developing Rat. Developmental Psychobiology, 17, 383-389. https://doi.org/10.1002/dev.420170405

[6] Korczyñski, R. and Korda, P. (1984) Immobility Reflex Evoked by Vertical Lifting of the Rat. Acta Neurobiologiae Experimentalis, 4, 144-159.

[7] Pellis, S.M., Teitelbaum, P. and Meyer, M.E. (1990) Labyrinthine and Visual Involvement in the Dorsal Immobility Response of Adult Rats. Behavioural Brain Research, 39, 197-204. https://doi.org/10.1016/0166-4328(90)90105-N

[8] Webster, D.G., Lanthorm, T.H., Dewsburry, D.A. and Meyer, M.E. (1981) Tonic Immobility and the Dorsal Immobility Response in Twelve Species of Muroid Rodents. Behavioral and Neural Biology, 31, 32-41.

https://doi.org/10.1016/0166-4328(90)90105-N

[9] Wilson, C., Cullen, E. and Sendell, K. (1984) A Pharmacology Investigation of the "Transport Response" in the White Rat. International Journal of Developmental Neuroscience, 2, 323-329. https://doi.org/10.1016/0736-5748(84)90068-6

[10] De La Cruz, F. and Junquera, J. (1989) Potentiation by Vestibular Stimulation of the Immobility Reflex Elicited by Clamping in Development and Adult Rats. Behavioural Brain Research, 34, 235-237. https://doi.org/10.1016/S0166-4328(89)80104-4

[11] De La Cruz, F., Junquera, J. and Russek, M. (1989) Ontogeny of Immobility Reactions Elicited by Clamping, Bandaging and Maternal Transport in Rats. Experimental Neurology, 97, 315-326. https://doi.org/10.1016/0014-4886(87)90092-6

[12] De La Cruz, F., Russek, M. and Junquera, J. (1990) Ontogenic of the Endorphinergic and Dopaminergic Modulation on the Immobility Reflex Elicited by Clamping in Rats. International Journal of Psychophysiology, 9, 171-177.

https://doi.org/10.1016/0167-8760(90)90071-K

[13] Brewster, J. and Leon, M. (1980) Facilitation of Maternal Transport by Norway Rat Pups. Journal of Comparative and Physiological Psychology, 94, 80-88.

https://doi.org/10.1037/h0077645

[14] Juryenczyk, J. and Jurkowski, A. (1990) A Case of Sporadic Hypokalemic Form of Familial Periodic Paralysis. Wiadomości Lekarskie, 43, 1148-1150.

[15] Santana, E., Jiménez, M., Vilanova, F. and Villar-Landeira, J.M. (1993) Anesthesia in a Case of Hiperkalemic Familial Periodic Paralysis. Revista Española de Anestesiología y Reanimación, 40, 26-28.

[16] Fontaine, B., Vale-Santos, J., Jurkat-Rott, K., et al. (1994) Mapping of the Hypokalemic Periodic Paralysis (HypoPP) Locus to Chromosome 1q31-32 in Three European families. Nature Genetics, 6, 267-272. https://doi.org/10.1038/ng0394-267

[17] Venance, S.L., Cannon, S.C., Fialho, D., et al. (2006) The Primary Periodic Paralyses: Diagnosis, Pathogenesis and Treatment. Brain, 129, 8-17.

https://doi.org/10.1093/brain/awh639 
[18] Cannon, S.C. (2015) Channelopathies of Skeletal Muscle Excitability. Comprehensive Physiology, 5, 761-790. https://doi.org/10.1002/cphy.c140062

[19] Fontaine, B. (1994) Primary Periodic Paralysis and Muscle Sodium Channel. Advances in Nephrology from the Necker Hospital, 23, 191-197.

[20] Johnson, C.H. and VanTassell, V.J. (1991) Acute Barium Poisoning with Respiratory Failure and Rhabdomyolysis. Annals of Emergency Medicine, 20, 1138-1142. https://doi.org/10.1016/S0196-0644(05)81393-9

[21] Koch, M., Appoloni, O., Haufroid, V., Vincent, J.L. and Lheureux, P. (2003) Acute Barium Intoxication and Hemodiafiltration. Journal of Toxicology: Clinical Toxicology, 41, 363-367. https://doi.org/10.1081/CLT-120022004

[22] Layzer, R.B. (1982) Periodic Paralysis and Sodium-Potassium Pump. Annals of Neurology, 11, 547-552. https://doi.org/10.1002/ana.410110602

[23] Lewi, Z. and Bar-Khayim, Y. (1964) Food Poisoning from Barium Carbonate. The Lancet, 284, 342-343. https://doi.org/10.1016/S0140-6736(64)90281-8

[24] Schaefer, T. (2005) Disorders of Potassium. Emergency Medicine Clinics of North America, 23, 723-747. https://doi.org/10.1016/j.emc.2005.03.016

[25] Gennari, F.J. (2002) Disorders of Potassium Homeostasis: Hypokalemia and Hyperkalemia. Critical Care Clinics, 18, 273-288. https://doi.org/10.1016/S0749-0704(01)00009-4

[26] Griggs, R.C., Resnick, J. and Engel, W.K. (1983) Intravenous Treatment of Hypokalemic Periodic Paralysis. Archives of Neurology, 40, 539-540.

[27] Griggs, R.C., Engel, W.K. and Resnick, J.S. (1970) Acetazolamide Treatment of Hypokalemic Periodic Paralysis. Annals of Internal Medicine, 73, 39-48. https://doi.org/10.7326/0003-4819-73-1-39

[28] Torres, C.F., Griggs, R.C., Moxley, R.T. and Bender, A.N. (1981) Hypokalemic Periodic Paralysis Exacerbated by Acetazolamide. Neurology, 31, 1423-1428. https://doi.org/10.1212/WNL.31.11.1423

[29] Lin, S.H. (2005) Thyrotoxic Periodic Paralysis. Mayo Clinic Proceedings, 80, 99-105. https://doi.org/10.1016/S0025-6196(11)62965-0

[30] Statland, J.M. and Barohn, R.J. (2013) Muscle Channelopathies: The Nondystrophic Myotonias and Periodic Paralyses. Continuum, 19, 1598-1614.

https://doi.org/10.1212/01.CON.0000440661.49298.c8

[31] Harel, Z. and Kamel, K.S. (2016) Optimal Dose and Method of Administration of Intravenous Insulin in the Management of Emergency Hyperkalemia: A Systematic Review. PLoS ONE, 11, e0154963. https://doi.org/10.1371/journal.pone.0154963

[32] Abu-Hamdan, D., Sondheimer, J. and Mahajan, S. (1985) Cautopyreiophagia. Cause of Life-Threatening Hyperkalemia in a Patient Undergoing Hemodialysis. The American Journal of Medicine, 79, 517-519. https://doi.org/10.1016/0002-9343(85)90042-7

[33] Gelfand, M., Zarate, A. and Knepshield, J. (1975) Geophagia. A Cause of Life Threatening Hyperkalemia in Patients with Chronic Renal Failure. JAMA, 234, 738-740.

[34] Bronson, W.R., DeVita, V.T., Carbone, P.P. and Cotlove, E. (1966) Pseudohyperkalemia Due to Release of Potassium from White Blood Cells during Clotting. The New England Journal of Medicine, 274, 369-375. https://doi.org/10.1056/NEJM196602172740702

[35] Ifudu, O., Markell, M.S. and Friedman, E.A. (1992) Unrecognized Pseudohyperkalemia as a Cause of Elevated Potassium in Patients with Renal Disease. American 
Journal of Nephrology, 12, 102-104. https://doi.org/10.1159/000168425

[36] Nijsten, M.W., de Smet, B.J. and Dofferhoff, A.S. (1991) Pseudohyperkalemia and Platelet Counts. The New England Journal of Medicine, 325, 1107. https://doi.org/10.1056/NEJM199110103251515

[37] Mansoor, S., Holtzman, N.G. and Emadi, A. (2015) Reverse Pseudohyperkalemia: An Important Clinical Entity in Chronic Lymphocytic Leukemia. Case Reports in Hematology, 2015, Article ID: 930379. https://doi.org/10.1155/2015/930379

[38] Singh, P.J., Zawada, E.T. and Santella, R.N. (1997) A Case of "Reverse" Pseudohyperkalemia. Mineral and Electrolyte Metabolism, 23, 58-61.

[39] Abraham, B., Fakhar, I., Tikaria, A., et al. (2008) Reverse Pseudohyperkalemia in a Leukemic Patient. Clinical Chemistry, 54, 449-451. https://doi.org/10.1373/clinchem.2007.095216

[40] Garwicz, D., Karlman, M. and Ora, I. (2011) Reverse Pseudohyperkalemia in Heparin Plasma Samples from a Child with T Cell Acute Lymphoblastic Leukemia with Hyperleukocytosis. Clinica Chimica Acta, 412, 396-397. https://doi.org/10.1016/j.cca.2010.10.023

[41] Meng, Q.H. and Krahn, J. (2011) Reverse Pseudohyperkalemia in Heparin Plasma Samples from a Patient with Chronic Lymphocytic Leukemia. Clinical Biochemistry, 44, 728-730. https://doi.org/10.1016/j.clinbiochem.2011.03.026

[42] Cavel-Greant, D., Lehmann-Horn, F. and Jurkat-Rott, K. (2012) The Impact of Permanent Muscle Weakness on Quality of Life in Periodic Paralysis: A Survey of 66 Patients. Acta Myologica, 31, 126-133.

[43] Sansone, V.A., Ricci, C., Montanari, M., Apolone, G., Rose, M. and Meola, G., INQoL Group (2012) Measuring Quality of Life Impairment in Skeletal Muscle Channelopathies. European Journal of Neurology, 19, 1470-1476. https://doi.org/10.1111/j.1468-1331.2012.03751.x

[44] Thiel, A., Wagner, M., Berh, R. and Hempelmann, G. (1993) Anesthesia in Familial Hiperkalemic Periodic Paralysis. Anesthesiol Intensivmed Notfallmed Schmerzther, 28, 125-127. https://doi.org/10.1055/s-2007-998891

[45] McGraw, C.P. and Klemm, W.R. (1969) Mechanisms of the Immobility Reflex (“Animal Hypnosis"). III. Neocortical Inhibition in Rats. Communications in Behavioral Biology, 3, 53-59.

[46] Bures, J. and Buresova, O. (1956) The Influence of Reflex Acoustic Epilepsy and Reflex Inhibition (“Animal Hypnosis”) by Spreading EEG Depression. The Journal of Physiology and Biochemistry, 5, 395-400.

[47] Teschke, E.J., Maser, J.D. and Gallup Jr., G.G. (1975) Cortical Involvement in Tonic Immobility (“Animal Hypnosis”): Effect of Spreading Cortical Depression. Behavioral Biology, 13, 139-143. https://doi.org/10.1016/S0091-6773(75)90928-1

[48] De La Cruz, F., Urióstegui, T., Zamudio, S., Pacheco, J., Garcia, M., Quevedo, L. and Chuc, E. (1995) Potentiation of the Immobility Response Elicited by Bandaging and Clamping in Mesencephalic Rats. Physiology \& Behavior, 58, 737-742. https://doi.org/10.1016/0031-9384(95)00123-Z

[49] Perlmutter, M. and Hall, E. (1992) Biological Changes across Adulthood. In: Adult Development and Aging, 2nd Edition, John Wiley and Sons, Hoboken, 81-119.

[50] Wu, F., Mi, W., Hernández-Ochoa, E.O., Burns, D.K., Fu, Y., Gray, H.F., Struyk, A.F., Schneider, M.F. and Cannon, S.C. (2012) A Calcium Channel Mutant Mouse Model of Hypokalemic Periodic Paralysis. Journal of Clinical Investigation, 122, 4580-4591. https://doi.org/10.1172/JCI66091 
[51] Zamudio, S.R., Quevedo-Corona, L., Garcés, L. and De La Cruz, F. (2009) The Effects of Acute Stress and Acute Corticosterone Administration on the Immobility Response in Rats. Brain Research Bulletin, 80, 331-336.

https://doi.org/10.1016/j.brainresbull.2009.09.005

[52] Morales-Dionisio, O., de la Cruz, F., Franco-Colín, M., Hidalgo-Alegría, O., Flores, G., Luna-Muñoz, J. and Garcés-Ramírez, L. (2017) Differential Effects of Valproic Acid on Immobility Responses and Locomotor Activity in Female and Male Rats. Journal of Pharmacy and Pharmacology, 8, 339-353.

https://doi.org/10.4236/pp.2017.810025

[53] Rüdel, R., Lehmann-Horn, F., Ricker, K. and Kuther, G. (1984) Hypokalemic Periodic Paralysis: In Vitro Investigation of Muscle Fiber Membrane Parameters. Mus cle \& Nerve, 7, 110-120. https://doi.org/10.1002/mus.880070205

[54] Jurkat-Rott, K., Weber, M.A., Fauler, M., Guo, X.H., Holzherr, B.D., Paczulla, A., Nordsborg, N., Joechle, W. and Lehmann-Horn, F. (2009) $\mathrm{K}^{+}$-Dependent Paradoxical Membrane Depolarization and $\mathrm{Na}^{+}$Overload, Major and Reversible Contributors to Weakness by Ion Channel Leaks. Proceedings of the National Academy of Sciences of the United States of America, 106, 4036-4041.

https://doi.org/10.1073/pnas.0811277106 